\title{
Towards the evaluation of a thermal compartmentation renovation concept through in-situ measurements
}

\author{
Twan Rovers ${ }^{1, *}$, Christian Struck', and Jeroen van 't Ende ${ }^{1}$ \\ ${ }^{1}$ Saxion University of Applied Sciences, School of Business, Building \& Technology, Chair of Sustainable Building Technology, \\ P.O. Box 70.000, $7500 \mathrm{~KB}$ Enschede, the Netherlands.
}

\begin{abstract}
Facing the energy transition, Dutch social housing corporations are expected to fulfil a pioneering role in realising fossil fuel free and $\mathrm{CO}_{2}$ neutral dwellings and neighbourhoods. However, given the high current costs of retrofitting dwellings to net zero energy, housing corporations are searching diligently for alternative, more affordable, renovation strategies. A Thermal Compartmentation renovation concept has been developed, in which retrofitting efforts are concentrated on the living spaces in dwellings. By means of co-heating tests, the quality of the thermal shell of three retrofitted case objects has been evaluated. It is found that both the airtightness and the heat loss coefficient (HLC) improved significantly as a result of the renovation. As would be expected, the realised 'warm compartments' show a better thermal performance than the entire dwellings. Although the measurements and subsequent analyses have confirmed the impact of the renovation measures on the buildings' thermal performance, additional research targeting the inhabited dwellings is necessary to draw up final conclusions on the potential of the Thermal Compartmentation renovation concept.
\end{abstract}

\section{Introduction}

Whilst European and national legislation to reduce the energy demand of newly built dwellings has become ever more stringent [1], it has been noted that the existing building stock possesses a large energy saving potential [2]. Indeed, the European building stock can be characterized as quite old: In the EU28 member states, $49 \%$ of the dwellings has been constructed before 1970 [3], i.e. before the first thermal standards for dwellings were introduced. If newly set climate goals [4] are to be achieved, it is thus imperative that existing buildings are energetically retrofitted.

In terms of age, the Dutch housing stock is similar to the EU28; $43 \%$ of the dwellings has been constructed before 1970 [3]. The Dutch housing stock is also characterized by a relatively large share $(33 \%)$ of tenant occupied dwellings [3]. This is one of the reasons why social housing corporations have been designated to fulfil a pioneering role in the Dutch energy transition [5]. However, given the high current costs of retrofitting dwellings to net zero energy (NZEB), housing corporations are searching diligently for alternative, more affordable, renovation strategies.

In the Thermal Compartmentation renovation concept, dwellings are compartmentalized in warm and cold zones (see Fig. 1). Renovation measures are applied in accordance with currently observed occupant patterns. That means that the warm compartment, i.e. the living spaces comprising the kitchen and living room, which dominates the energy demand for space heating, is thermally insulated well. The cold compartment, on the other hand, is hardly heated in practice and is thus not insulated additionally. Locally generated renewable energy is used to meet the demand for the remaining energy.

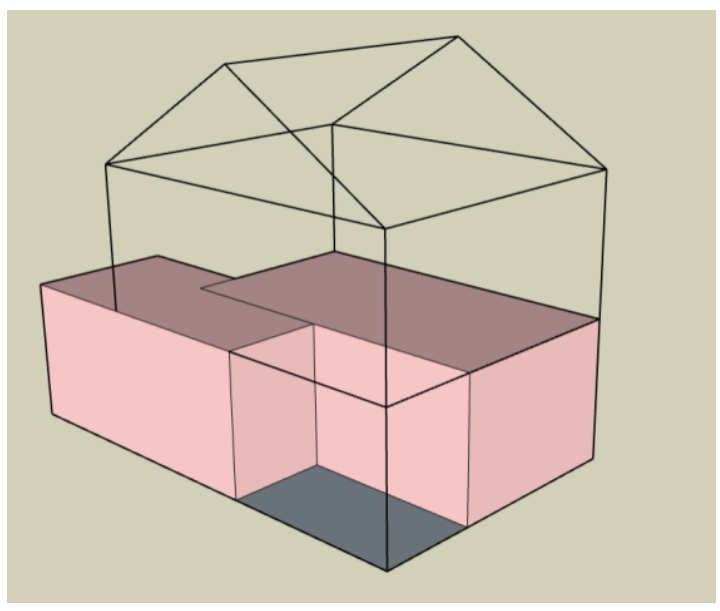

Fig. 1. Compartmentation in warm (red) and cold (transparent) zones

The effect of thermal compartmentation, or other renovation strategies, may be predicted using building performance simulations. However, considering the

* Corresponding author: t.j.h.rovers@saxion.nl 
limitations of models and limited knowledge of actual occupancy patterns contributing to the performance gap phenomenon [6-8], it is imperative to conduct measurements to assess whether the actual performance of a renovated dwelling is as anticipated.

\section{Research method}

The Thermal Compartmentation renovation concept is evaluated using case study research of three dwellings (year of construction: 1955) in the east of the Netherlands; one terraced dwelling (case object 1), one end-of-terrace dwelling (case object 3 ), and one terraced house with a passageway to the backyard, see Fig. 2 .

The performance of the thermal shell of the three case objects is assessed by means of co-heating tests. For two of the case objects ( 1 and 3 ), the performance of the thermal shell is assessed prior to the application of the renovation measures.

The renovation measures were directed at the living spaces (i.e. living room and kitchen) and comprised the installation of high performance glazing and doors, internal wall insulation with a high-performance (aerogel based) insulation material, insulation of the ceiling using loose-fill mineral wool and various air tightening measures. In case object 3, a new (insulated) ground floor was installed in addition.

After the renovation, two co-heating tests were applied to all three case objects: one directed at the entire building, and one directed at the warm compartment. The airtightness of the building and warm compartment were measured prior to and after each co-heating test, by means of blower door tests.

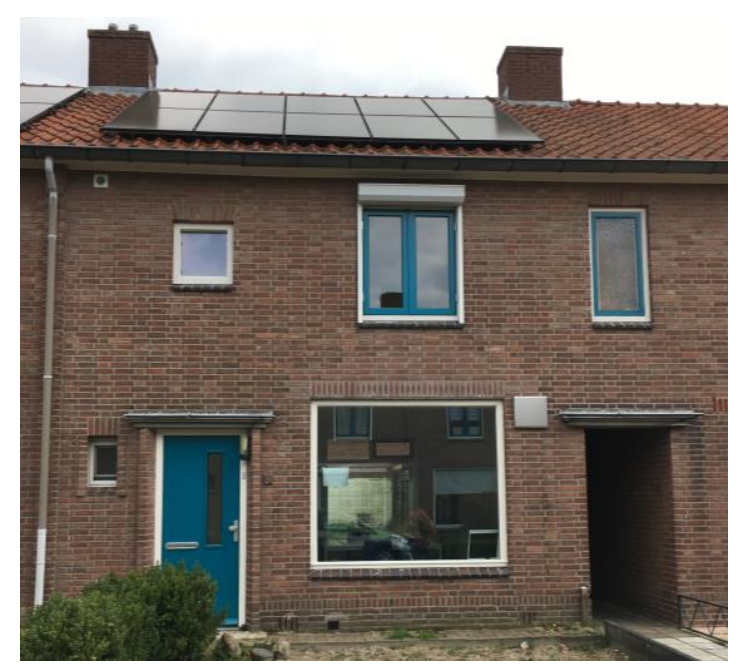

Fig. 2. Case object 2

In a co-heating test [9], the indoor environment of a vacant building is heated to a fixed elevated temperature. The energy used for heating $\left(\mathrm{Q}_{\mathrm{h}}\right)$, as well as indoor and outdoor conditions are monitored during the measurement campaign, which allow for the estimation of the solar heat gain $\left(Q_{s}\right)$ (through the procedures as described in [10]) and infiltration heat loss $\left(Q_{\mathrm{v}}\right)$ as a result of wind pressure on the building. The last unknown parameter in a simplified energy balance (see Fig. 3), the transmission heat loss $\left(\mathrm{Q}_{\mathrm{t}}\right)$, can then straightforwardly be calculated.

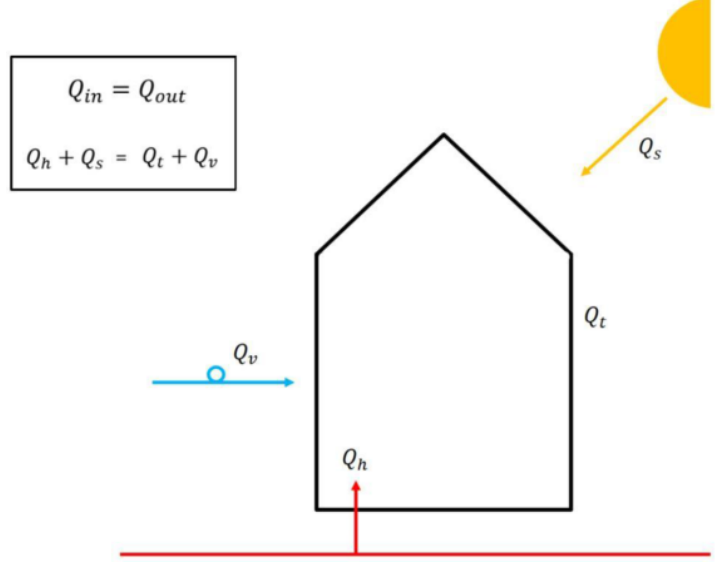

Fig. 3. Heat balance for co-heating tests

The Heat Loss Coefficient (HLC) can be calculated as follows:

$$
Q_{h}+Q_{s}=H L C \times \Delta T
$$

Where in the case of a detached house, the difference $(\Delta \mathrm{T})$ between the indoor and outdoor temperature is used, this is complicated when considering terraced houses due to the presence of neighbouring zones [11]. In the case objects under consideration, these neighbouring zones comprise adjacent dwellings, crawl spaces, sheds and - in the case of compartmentalized dwellings - the entire cold compartment.

In the absence of a complete set of heat flow measurements to all neighbouring zones, the temperature difference is weighted over the relevant surface areas (A) and theoretical thermal transmittances (U), as well as thermal bridges $(\psi)$ and their length $(\mathrm{L})$. This is done for every relevant partition construction $\mathrm{n}$ :

$H L C=\left(Q_{h}+Q_{s}\right) / \Sigma\left[(U \times A+\psi \times L)_{n} / \Sigma(U \times A+\psi \times\right.$ L) $] \times \Delta T_{n}$

Alternatively, the heat flows to all relevant neighbouring zones can be calculated based on the surface area of the partition construction, its theoretical U-value and the measured temperature in the neighbouring zones (nz). These heat flows can then be subtracted from the heat input, after which an HLC can be calculated which is solely dependent on the temperature difference between indoor and outdoor.

$$
Q_{h}+Q_{s}-\Sigma Q_{n z}=H L C \times \Delta T
$$

\section{Results and analyses}

Table 1 shows the results of the airtightness measurements and co-heating tests, both per square meter floor area. 
As a result of the renovation, the airtightness of the case objects, in particular regarding the warm compartment, has improved significantly. This, in part, has contributed to the improvement of the HLC of the dwellings.

Table 1. Results of airtightness measurements and co-heating tests

\begin{tabular}{lcccc} 
Case object & \multicolumn{2}{c}{ Before renovation } & \multicolumn{2}{c}{ After renovation } \\
& $\begin{array}{c}\mathrm{q}_{\mathrm{v} ; 10} \\
1 \mathrm{~s}^{-1} \mathrm{~m}^{-2}\end{array}$ & $\begin{array}{c}\mathrm{HLC} \\
\mathrm{W} \mathrm{K}^{-1} \mathrm{~m}^{-2}\end{array}$ & $\begin{array}{c}\mathrm{q}_{\mathrm{v} ; 10} \\
1 \mathrm{~s}^{-1} \mathrm{~m}^{-2}\end{array}$ & $\begin{array}{c}\text { HLC } \\
\mathrm{W} \mathrm{K}^{-1} \mathrm{~m}^{-2}\end{array}$ \\
\hline 1 - dwelling & 6.57 & 5.94 & 5.15 & 4.67 \\
1 - warm. c. & & & 1.07 & 5.97 \\
\hline 2 - dwelling & & & 5.77 & 5.01 \\
2 - warm. c. & & & 0.68 & 6.34 \\
\hline 3 - dwelling & 8.39 & 6.40 & 6.90 & 4.87 \\
3 - warm. c. & & & 0.65 & 5.65
\end{tabular}

Whilst the HLC of the warm compartment after renovation may seem high, it is noted that the building shell to floor surface ratio is much higher for the warm compartment (4.2) than for the entire dwelling (2.8). When the HLC is expressed per square meter thermal shell (ts, see Table 2), it becomes apparent that the warm compartment has a better thermal performance than the entire dwelling for each of the three case objects, which would be expected considering the applied renovation measures.

Table 2. Results of co-heating tests, weighted $\Delta \mathrm{T}$ (HLC per $\mathrm{m}^{2}$ thermal shell)

\begin{tabular}{lcc} 
Case object & $\begin{array}{c}\text { Before renovation } \\
\text { HLC } \\
\mathrm{W} \mathrm{K}^{-1} \mathrm{~m}^{-2} \text { ts }\end{array}$ & $\begin{array}{c}\text { After renovation } \\
\text { HLC } \\
\mathrm{W} \mathrm{K}^{-1} \mathrm{~m}^{-2} \text { ts }\end{array}$ \\
\hline 1 - dwelling & 2.12 & 1.66 \\
1 - warm. c. & & 1.44 \\
\hline 2 - dwelling & & 1.79 \\
2 - warm. c. & & 1.52 \\
\hline 3 - dwelling & 2.28 & 1.74 \\
3 - warm. c. & & 1.36
\end{tabular}

Adopting the alternative approach as described in Section 2, in which the heat flows to all neighbouring zones are subtracted from the heat input of the heaters $\left(\mathrm{Q}_{\mathrm{h}}\right)$ and solar gains $\left(\mathrm{Q}_{\mathrm{s}}\right)$, smaller HLC values are found (see Table 3).

Table 3. Results of co-heating tests, subtracted heat flows to neighbouring zones (HLC per $\mathrm{m}^{2}$ thermal shell)

\begin{tabular}{lcc} 
Case object & $\begin{array}{c}\text { Before renovation } \\
\text { HLC } \\
\mathrm{W} \mathrm{K}^{-1} \mathrm{~m}^{-2} \text { ts }\end{array}$ & $\begin{array}{c}\text { After renovation } \\
\text { HLC } \\
\mathrm{W} \mathrm{K}^{-1} \mathrm{~m}^{-2} \text { ts }\end{array}$ \\
\hline 1 - dwelling & 0.124 & 0.062 \\
1 - warm. c. & & 0.017 \\
\hline 2-dwelling & & 0.090 \\
2 - warm. c. & & 0.019 \\
\hline 3 - dwelling & 0.143 & 0.128 \\
3 - warm. c. & & 0.026
\end{tabular}

The HLCs of the warm compartments of case objects 1 and 2 are similar, 0.017 and $0.019 \mathrm{~W} \mathrm{~K}^{-1} \mathrm{~m}^{-2}$ ts, respectively. This would be expected, as the same renovation measures have been applied to the case objects. An exception is that in case object 3, the existing ground floor was replaced by an insulated floor. However, this does not seem to result in a lower HLC compared to the other two case objects.

In addition to the HLC calculations, the measured transmission heat losses $\left(\mathrm{Q}_{\mathrm{t}}\right)$ may be compared with the results of transmission heat loss calculations based on theoretical $U$ and $\psi$ values, and measured temperatures. Table 3 shows these results for the warm compartments.

It is noted that the method used for splitting the heat losses in transmission $\left(\mathrm{Q}_{\mathrm{t}}\right)$ and infiltration $\left(\mathrm{Q}_{\mathrm{v}}\right)$ heat losses, i.e. estimating $Q_{v}$ based on measurements of wind velocity and wind direction to determine wind pressure on the building, provides only indicative results. It has been found that, in particular with the high air permeability's that have been measured in the dwellings (see Table 1), this method tends to overestimate the infiltration heat loss.

Table 3. Results of co-heating tests (HLC per $\mathrm{m}^{2}$ thermal shell)

\begin{tabular}{lccc} 
Case object & $\begin{array}{c}\text { Theor. } \mathbf{Q}_{\mathbf{t}} \\
\mathrm{kW}\end{array}$ & $\begin{array}{c}\text { Meas. } \mathbf{Q}_{\mathbf{t}} \\
\mathrm{kW}\end{array}$ & $\begin{array}{c}\text { Difference } \\
\%\end{array}$ \\
\hline 1 - warm. c. & 2.01 & $1.72 *$ & $-14 \%$ \\
2 - warm. c. & 1.58 & 1.82 & $+15 \%$ \\
3 - warm. c. & 1.16 & 1.55 & $+34 \%$
\end{tabular}

For the warm compartment of case object 1 , it is found that the measured transmission heat loss is lower than what would be expected based on the theoretical transmission heat loss calculation. For case objects 2 and 3, a larger $Q_{t}$ has been measured. Thermographic inspections have not revealed major thermal bridges which have not been included in the calculations. In-situ measurements of thermal transmittances [12] may reveal deviations in theoretical and actual U-values.

\section{Discussion and conclusion}

A limitation of the present study is the absence of a complete set of heat flow measurements to neighbouring zones. In order to be able to calculate an HLC nonetheless, a method was adopted to use a weighted temperature difference, using theoretical heat transmission properties of all construction parts. It must be noted that with this approach, the HLC loses its physical meaning, i.e. $\Delta \mathrm{T}$ does not refer to the difference between the indoor and outdoor temperature with this approach.

The physical meaning of the HLC is maintained by using the alternative approach as discussed in Section 2, in which the heat flows to all neighbouring zones are subtracted from the heat input of the heaters $\left(Q_{h}\right)$ and solar gains $\left(\mathrm{Q}_{\mathrm{s}}\right)$. It is noted that the results of this approach remain largely theoretical, as theoretical U- 
values of the partition constructions were used in the absence of measurements.

Nevertheless, the measurements and subsequent analyses indicate that the thermal performance of the dwellings has been improved as a result of the renovation measures; both the airtightness and the heat loss coefficient (HLC) improved significantly. As would be expected, the warm compartments show a better thermal performance than the entire dwellings. A comparison of theoretical and measured transmission heat losses, shows deviations between these. More research is required to identify the underlying cause(s).

Additional measurements are to be conducted to draw up final conclusions on the potential of the Thermal Compartmentation renovation concept. The manner in which the building is used, e.g. heating of the different zones, will have a large impact on the buildings' energy use. Future research efforts will therefore be directed at the inhabited dwellings, in which the energy use for the heating of the warm and cold compartments, as well as domestic hot water are monitored separately.

The authors wish to acknowledge the financial support of the Dutch Ministry of Economic Affairs (Topsector Energiesubsidie, TKI Urban Energy, project number TEUE018013).

\section{References}

1. A.M. Papadopoulos, Energy and Buildings, 37, 77$86(2005)$

2. C. Petersdorff, T. Boermans, J. Harnisch, ESPR, 13, 350-358 (2006)

3. European Commission, EU Buildings Database (2019)

4. Paris Agreement (2015)

5. Klimaatberaad (2019)

6. C. Struck, M. Benz, V. Dorer, B. Frei, M. Hall, M. Menard, S. Moosberger, K. Orehounig, C. Sagerschnig, Status-Seminar: Forschen für den Bau im Kontext von Energie und Umwelt, 1-10 (2014)

7. D. Majcen, L.C.M. Itard, H. Visscher, Energy Policy, 54, 125-136 (2013)

8. D. Majcen, L.C.M. Itard, H. Visscher, Energy Policy, 97, 82-92 (2016)

9. G. Bauwens, S. Roels, Energy and Buildings, 82, 163-172 (2014)

10. J.A. Duffie, W.A. Beckman, Solar Engineering of Thermal Processes (2013)

11. G. Bauwens, S. Roels, Energy Procedia, 132, 339344 (2017)

12. ISO 9869 (2014) 